\title{
A Test System Model for Stability Studies of UK Power Grid
}

\author{
Linash P. Kunjumuhammed \\ Department of Electrical and \\ Electronic Engineering \\ Imperial College London \\ United Kingdom \\ linash.p.k@imperial.ac.uk
}

\author{
Bikash C. Pal \\ Department of Electrical and \\ Electronic Engineering \\ Imperial College London \\ United Kingdom \\ b.pal@imperial.ac.uk
}

\author{
Nina F. Thornhill \\ Department of Chemical Engineering \\ Imperial College London \\ United Kingdom \\ n.thornhill@imperial.ac.uk
}

\begin{abstract}
The paper presents a test system model to study the effect of variable wind power output on the stability of future power systems. The test system is built upon a future UK transmission system model and it contains different types of generators, HVDC transmission lines, and interconnections. A poorly damped inter-area mode is present in the test system that closely resembles the Scotland-England inter-area mode existing in the UK transmission system. The study system will help to analyze the impact of increased variability in power system operating conditions on the oscillatory mode.
\end{abstract}

Index Terms-Power system dynamics, modeling, DFIG, FACTS, HVDC

\section{INTRODUCTION}

Like many countries around the world, the United Kingdom (UK) is committed to source most of its future energy requirements from renewable resources. The climate change act of 2008 sets a binding goal to reduce UK's green house gas emission by at least $80 \%$ below the 1990 baseline by 2050, and the Renewable energy directive of 2009 sets a target for the UK to achieve 15\% of its total energy consumption from renewable sources by 2020 [1]. At the same time, in order to comply with Large Combustion Plant Directives (LCPD) around 8-13GW of coal, oil and gas power plants will be closed by 2015 [2], [3]. Post 2015, the Industrial Emission Directive (IED) will impose further constraints over operation of coal based thermal power plants [4]. Also aging nuclear power plants will be closed and new nuclear projects are in planning stage. Altogether several conventional power plants will be closed in this decade. New interconnections will be commissioned within the network and with neighboring countries, which will improve reliability and increase access to the evolving European energy market.

These changes will make the future GB transmission network unique in many aspects. Large penetration of wind power with changing wind velocity, direction and location will shift the generation concentration from one part of the system to another. Subsequently power flow pattern in the network will experience large variation. The network will play a major role in the evolving European electricity market through which large amount of wind generation from Scotland, Offshore England and Ireland will be transmitted to Continental Europe. Also, the island network with several HVDC interconnections with external grids, internal HVDC transmission lines, and offshore HVDC networks, will give rise to a power system with comparatively high concentration of FACTS devices. These devices can offer various supplementary control features to improve reliability and stability of power system. At the same time they can cause new problems in the network. This will make the UK system operation unique and from an academic perspective an ideal choice to study power system operational challenges. However, obtaining a network model is seldom easy for academic research due to proprietary rights. This work is important in this context.

The paper discusses future generation scenarios in the GB network and proposes a framework for developing a dynamic test system model. Using this approach a representative GB network (RGBN) model is developed. The model is used to simulate scenarios that can provide insights into the way in which system dynamics will be affected by increased use of wind generation and new HVDC lines.

\section{OVERVIEW OF FUTURE GB NETWORK}

GB network consists of an onshore transmission network covering England, Wales and Scotland, and an offshore transmission network. A large share of its installed generation capacity $(\approx 85 \mathrm{GW})$ consists of non-renewable sources such as gas/CHP $(\approx 31 \mathrm{GW})$, coal $(\approx 25 \mathrm{GW})$ and nuclear $(\approx 10 \mathrm{GW})$ [1]. Only $\approx 8 G W$ capacity is accounted for by renewable generation. The proportion of generation mix is expected to reverse towards the middle of the next decade due to development of several renewable generation plants and closure of coal and oil plants which are close to the end of their working life or unable to meet the emission targets [5]. New gas and nuclear plants will be built to support reliability and security of supply. But the pace of these developments depends on other factors such as economic performance of the country and general technological progress, e.g. in the development of electric vehicles, advanced heating systems and energy efficient technologies. Some of the planned generation projects may be canceled or delayed due to various reasons. Considering these uncertainties National Grid has drawn up three scenarios for future GB network namely, Slow Progression Scenario (SPS), Gone Green Scenario (GGS), and Accelerated Growth Scenario (AGS) [6].

Fig. 1 shows the generation profile for various technologies under the three scenarios. The GGS represents a balanced approach in which the targets for 2020, 2030 
and 2050 are met through contributions from all generation sectors. The scenario assumes that the economy is expected to grow by $0.2 \%$ from 2012 and is not expected to increase by over $2 \%$ until 2015. The SPS and AGS assume a slower and faster growth in economy, respectively, and accordingly assume a relatively slower or faster growth in renewable generation. The key difference between the scenarios is a delay in achieving the emission and renewable targets. In the SPS, the 2020 target will not be achieved until some time between 2020 and 2025 whereas assuming a faster growth in the economy and the renewable generation the AGS projects an earlier date for achieving the target.

Fig. 1(a) and Fig. 1(b) show the change of generation and demand connected at transmission level respectively, under the three scenarios. The generation growth under SPS, GGS and APS are $102 \mathrm{GW}, 130 \mathrm{GW}$, and $155 \mathrm{GW}$, respectively by 2032 . The transmission connected demand is showing a different trend. Due to the double dip recession in 2011, the electricity demand reduced to $56.1 \mathrm{GW}$ in $2011 / 2012$. Because of poor economic growth no significant increase in transmission demand is predicted under all the three scenarios.

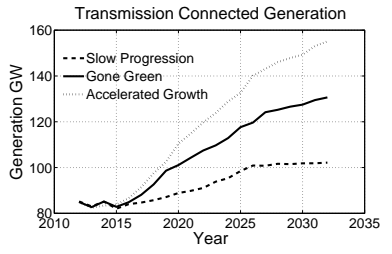

(a)

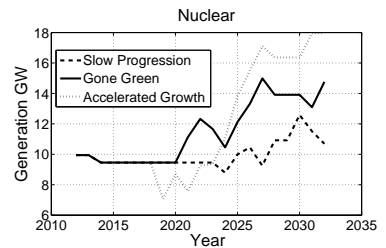

(c)

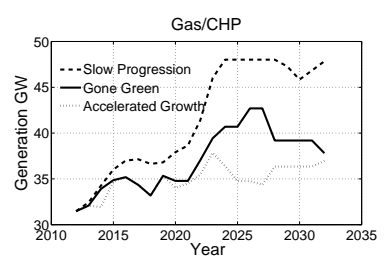

(e)

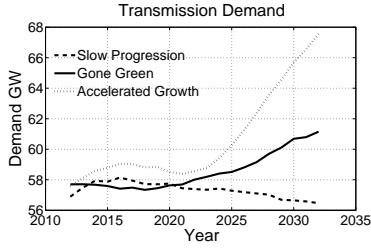

(b)

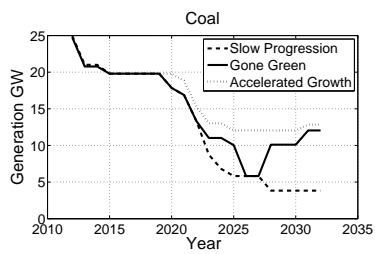

(d)

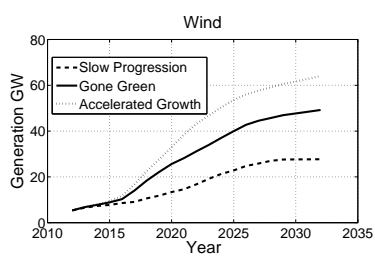

(f)
Fig. 1: Future generation scenarios in the GB network. Source: National Grid Electricity Ten Year Statement

\section{A. Nuclear}

Nuclear energy plays an important role in GB's future low carbon energy mix. Currently the GB system has got eight nuclear power plants producing close to $9 \mathrm{GW}$ of power. All the existing plants except one are scheduled to close down by 2023. In 2011 the UK government announced eight sites for constructing new nuclear power plants [7]. Fig. 2 shows the existing and future nuclear power plants with capacity. Out of eight sites, only five of them are in planning stage. The new plants may be delayed due to the government's reluctance to fund new nuclear projects, rising

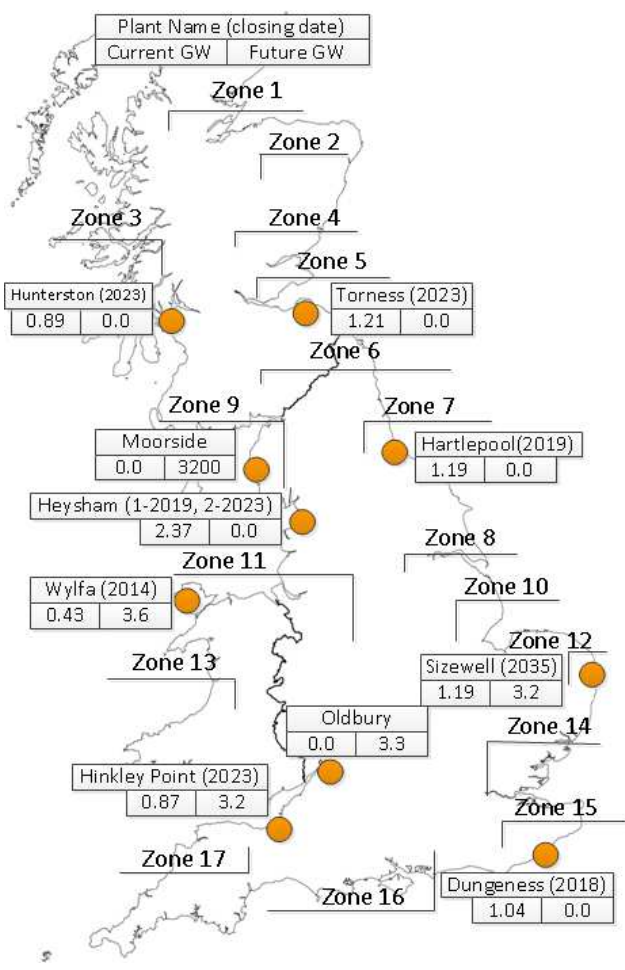

Fig. 2: Approximate location of GB system study zones and nuclear power plants. Source edfenergy.com

cost of building new plant, access to finance [8], [9], [10] etc.

National Grid's forecasts for nuclear generation developed under various scenarios are plotted in Fig. 1(c). The dip in graph after 2018 indicates the closure of existing plants and the positive slope indicates introduction of new generating stations post 2020. The GGS assumes that the first new nuclear power station will come into operation by early 2020 s and the capacity will reach $10 \mathrm{GW}$ by 2030 . Under SPS the first new nuclear plant will start its operation by mid-2020s. However the latest developments indicate that this plan may be delayed [9].

\section{B. Coal}

Bulk amount of electricity generation $(\approx 26 \mathrm{GW})$ in the UK comes from large coal fired thermal power plants. They played a significant role in ensuring energy security at low cost for several decades. During the last two decades Combined Cycle Gas Turbine (CCGT) generating stations have replaced some of the share of coal fired generation [11]. Some of the existing generating plants are planning to close on or before 2015 to comply with LCPD [3]. Under LCPD, all combustion plants built after 1987 should comply with new emission targets and existing power plants (built before 1987) have the option to opt out. Several coal plants have decided to opt out and will cease to operate before 2015 [3], [4], [12], [13], [14]. There are plans to convert some coal plants to biomass technology [12]. Post 2015, the coal power plants have to comply with more stringent emission rules under IED and additional investment is required for emission reduction.

Fig. 1(e) shows the coal generation profile under the three scenarios. In all cases, thermal generation output falls 
between 2013 and 2015 representing the opted out plants under LCPD. The output is expected to stay constant for the remaining part of the decade and about $9 \mathrm{GW}$ of coal power plants are expected to close under the SPS and GGS by 2023. However this closure could occur earlier than expected [4]. The increase in generation by the middle of next decade shows the development of carbon capture and storage plants. Introduction of this technology is dependant on the performance of the economy and technological progress.

\section{Gas/ CHP}

Electricity generation from CCGT increased steadily from the early 90's by replacing the capacities of conventional thermal and other generating stations [11] and their capacity will continue to grow in the future. Fig. 1(e) shows the projected gas/ CHP based electricity generation under various scenarios. In SPS, the gas based generation will increase from the current level of $33 \mathrm{GW}$ to $40 \mathrm{GW}$ and $49 \mathrm{GW}$ by 2020 and 2032 respectively. However, their contribution will be smaller in case of the GGS and AGS. In the GG scenario only 6GW increase is expected between 2012 and 2032 whereas the AGS estimates an increase of about $5 \mathrm{GW}$.

\section{Wind}

At present, wind supplies around 5\% of UK's electricity demand and it is expected to grow and may become the biggest contributor to electricity in the UK after natural gas in 2020 [15]. Fig. 1(f) shows projected growth in wind generation, onshore plus offshore, under the various scenarios.

1) Onshore Wind: Onshore wind is one of the most mature renewable energy technologies in the UK with an installed capacity of 5GW at the middle of 2012. An additional capacity of $1.8 \mathrm{GW}$ is under construction, $3.9 \mathrm{GW}$ is approved and $6.9 \mathrm{GW}$ is in planning [15]. Majority of this resource is located in Scotland and Wales. Under GGS and AGS, onshore wind is expected to contribute around 9GW by 2020 and under SPS it is projected to reach 7GW. One of the hurdles in onshore wind development is obtaining project consent as current figures suggest an average success rate close to $50 \%$ [16], [17].

Greenwire Project: The Greenwire project requires special attention, since plans are to build a $3 \mathrm{GW}$ onshore wind farm in Ireland and connect via a subsea cable to the GB grid [18]. From power system perspective, this wind farm can be considered as an offshore wind farm.

2) Offshore Wind: The UK offshore wind industry is one of the largest in the world with around 1.9GW of operating capacity. An additional capacity of $2.3 \mathrm{GW}$ is under construction, $1.2 \mathrm{GW}$ is approved and $5 \mathrm{GW}$ is in planning [15]. The Crown Estate has so far leased out several sea beds for wind farm sites with an aggregate potential capacity of 51GW [1]. The GGS estimate around $17 \mathrm{GW}$ of offshore wind capacity by 2020 and a capacity of 37GW by 2032 . However, cost, access to finance, economic situation, delay in getting planning permission etc. may affect their growth rate.

\section{E. Tidal/ Wave}

The UK wave and tidal potential is estimated to supply around $27 \mathrm{GW}$ of clean power by 2050 [5]. The technology

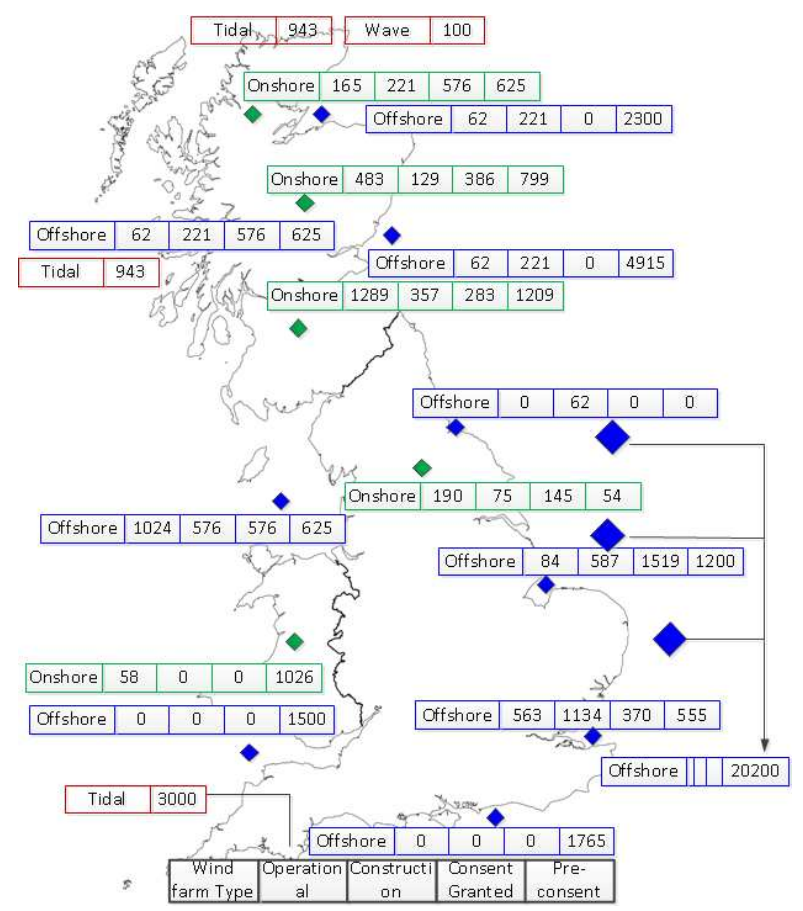

Fig. 3: Approximate location, and current and proposed generation capacity of wind, tidal and wave power generation sites

is in an early stage of development with around 4MW of prototypes currently undergoing testing. Under the GGS, the generation will grow to $20 \mathrm{MW}$ by 2020 and $1.2 \mathrm{GW}$ by 2032 [1].

\section{F. Transmission lines and Interconnections}

Transmission line capacity expansion is crucial to avoid possible bottlenecks in the system and to provide higher connectivity for renewable generation. In the GB system several projects for upgrading existing lines and construction of new lines are in progress or planning stage [1]. A notable addition is two HVDC transmission lines between Scotland and England which will expand the main transmission corridor in the system. Also several new interconnections with neighboring countries are in planning phase, that will help to improve GB's position in single European energy market. Table I lists existing and some planned interconnections. The recently commissioned East west interconnection will provide connectivity for wind farms in Ireland to the single market. From system operating point, this will cause large variations in operating conditions as interconnections will work in both import or export mode.

\section{G. Distribution of generation in future GB system}

So far the discussion is concentrated on the amount of generation by technology. However for power system dynamic performance distribution of future energy mix is very important. With large scale non dispatchable generation, network generation will change from a relatively predictable/ controllable generation portfolio to an uncertain and highly variable one. Uncertainty with regard to quantity, type and location of generation capacity may give rise to different estimates for the performance of the system.

Fig. 3 shows location and capacity of wind, tidal and wave power generation. An approximate transmission connected 
TABLE I: Existing and proposed interconnections in GB system

\begin{tabular}{|l|c|c|c|c|}
\hline Name & Areas connected & Capacity & Status & Connecting zone \\
\hline BritNed & Netherlands and UK & $1 \mathrm{GW}$ & Operational & Zone 15 \\
IFA & France and UK & $2 \mathrm{GW}$ & Operational & Zone 15 \\
Moyle Interconnector & Scotland and Northern Ireland & $500 \mathrm{MW}$ & Operational & Zone 6 \\
East-West Interconnector & Ireland and UK & $500 \mathrm{MW}$ & Operational & Zone 9 \\
Western HVDC Link & England and Scotland & $2.2 \mathrm{GW}$ & Construction & Zone 3,9 \\
Eastern HVDC link & England and Scotland & $2 \mathrm{GW}$ & Planning & Zone 2, \\
Nemo Interconnector & UK and Belgium & $1 \mathrm{GW}$ & Planning & Zone 15 \\
Norway Interconnector & Scotland and Norway & $1.4 \mathrm{GW}$ & Planning & Zone 7 \\
\hline
\end{tabular}

capacity is indicated for onshore wind farms. A significant portion of onshore wind capacity will be built in Scotland and Wales. Offshore, wave and tidal capacity are being constructed around the boundary of the system. The changing wind pattern will introduce a shift in power center and can pose a significant challenge to system operation. As evident from Fig. 2 future nuclear generation will be confined to the England side of the system. The conventional coal and gas power plants distributed through the system will play a system supporting role during high wind periods and be a major source of electricity during low wind. However, no difference is anticipated in location of major load centers. The participation of wind farms from Scotland and Ireland in the single energy market will introduce further uncertainty to network operation.

Zonal distribution of different types of generation is developed considering the generation level in 2013 and future expected generation level in 2023. Accordingly they are called 2013 scenario and 2023 scenario, respectively. Approximate location of 17 GB system study zones are shown in Fig. 2. [1] is used as the main source of data along with various generator operator's web sites. The oil and gas based generation are clubbed together because of their similar operational and dynamic characteristics. The 2013 generating scenario is created by adding generation existing generation and plants under construction, and a 2023 scenarios is created using; 2023 generation = Existing generation + Plants Under Construction $+75 \%$ of Plants with Consent Granted $+50 \%$ of plants Awaiting Consent + $25 \%$ of plants in Scoping - Decommissioning plant capacity. The formula is not followed for coal and nuclear power plant. For coal, no capacity addition is considered as new clean coal technology may not be available by 2023 . For the nuclear plants closing before 2020 the capacity in 2023 is set to zero and for others no change is made with an assumption that they will be phased out along with the introduction of new nuclear power plants after 2023.

\section{TEST SYSTEM DEVELOPMENT}

This section explains the development of the RGBN model. The skeleton for this model is obtained from a RGBN power flow model developed at University of Strathclyde [19], [20]. Fig. 4 shows a single-line diagram of the model consisting of 29 nodes, inter-connected through 98 transmission lines in double circuit configuration, and one single circuit transmission line. It contains 65 generators of various generation types. These network branches are intended to represent the main routes on which power flows across the

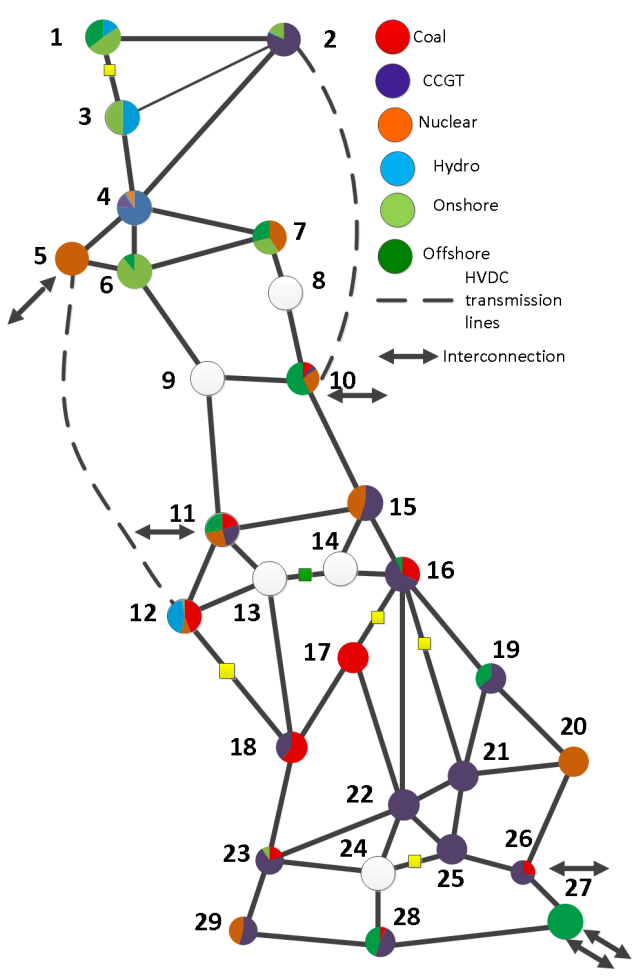

Fig. 4: Representative GB transmission network

GB transmission system and over which power is exchanged between the seven year statement's (SYS) "Study Zones" and have realistic parameters including thermal ratings. It is claimed that, the model is based on and has been validated against a solved AC Load Flow reference case that was provided by NGET [20].

\section{A. Generation mix in RGBN model}

The zonal distribution of different generation in actual system is compared with nodes of Fig. 4 and generation from the zones are distributed to the nodes according to their respective locations in GB system. For the test system, only CCGT, coal, hydro, nuclear, offshore wind and onshore wind based generation are considered. The CHP and biomass plant capacity is added to the coal capacity, and tidal and wave capacity are added to the offshore wind capacity. This is because, their capacities are not significant enough to be represented separately. However, when large scale tidal plants such as Alderney Renewable Energy [21] become fully operational, a separate tidal generator can be included to capture it's operating characteristics. This grouping will serve two purposes; 
- Distinct scheduling can be allotted for generators based on their technology to generate realistic operating conditions. For example, the nuclear power plants will operate as base load plants while hydro will be supporting peak load. Similar argument is true for wind farms as the wind characteristics at each wind farm are unique.

- Unique dynamic parameters can be assigned for generators depending on technology. For example, a steam and a gas power plant of similar capacity will have different inertia. Also, though the technology is same, the influence of offshore and onshore wind farm on grid will be different owing to its distance from the grid connection point.

This procedure is carried out for both the 2013 and the 2023 generation scenario to make two test systems. Table II list 56 generators of various generation types connected to the nodes in the RGBN model.

\section{B. Transmission system for RGBN model}

The network diagram shown in Fig. 4 is used as base transmission system where each node represents a $400 \mathrm{kV}$ bus. The generators are connected to one of the nodes through a generator bus and transformer/ transmission line. A HVDC system for offshore wind farm is not considered at present. The two HVDC transmission systems and 6 interconnections are included in the system.

\section{MOdAl ANALYSis OF RGBN MODEL}

This section presents modeling of RGBN model and analysis of the Scotland England inter-area mode. The synchronous machines are represented using a transient model and recommended range of values for different generator parameters are obtained from [22]. The inertia for gas turbine generators, steam turbine generators, and hydro generators are selected between $4 \mathrm{pu} \& 6 \mathrm{pu}$, between $6 \mathrm{pu} \& 10$, and $3 \mathrm{pu}$, respectively. The wind turbine generators are represented using the generic Type-4 WTG model [23].

The simulation study is carried out using MATLAB/ Simulink software. The system is linearized using linmod command and eigenvalues of the state matrix are obtained. The participation factor analysis shows that an inter-area mode with participation from synchronous generators located in both Scotland and England is present in the system. Table III shows the characteristics of the Scotland England inter-area mode under five selected operating conditions. The interconnections are not used for these cases for simplicity. Nuclear power plant output is set to $95 \%$ for all scenarios.

1) Case 1: Case 1 represents the RGBN test system with the 2013 generation and transmission system. The wind farms are operating at $70 \%$ of their capacity and other generators are supporting remaining load. The interarea mode damping and frequency are $7.36 \%$ and $0.69 \mathrm{~Hz}$, respectively.

2) Case 2: This case represents the 2023 generation model but output of wind generators are zero due to no wind. HVDC lines between Scotland and England are not used in this scenario and ac inter-area power transmission is close to Case 1. The damping is poor in this case. However, introduction of HVDC lines is found to improve damping by reducing load in the ac transmission system.
3) Case 3: In this case, all wind farms are working at $70 \%$ of rated capacity. The HVDC lines are transmitting additional wind power from Scotland, and Coal and CCGT plant output is reduced. No significant improvement in damping is observed as ac inter-area transmission lines are loaded as in the previous case.

4) Case 4: In this case wind farms in Scotland and England are operating at $70 \%$ and $10 \%$ capacity, respectively. The inter-area power flow is equal to Case 3 and the conventional power plants in England are making more power compared to Case 3. The damping and frequency of the mode in this case is very close to that of Case 3.

5) Case 5: In this case wind farms in Scotland and England are operating at $10 \%$ and $70 \%$ capacity, respectively. Lower generation in Scotland reduces the inter-area power flow and shows an improvement in the inter-area mode damping compared to the previous cases.

TABLE III: Scotland England inter-area mode characteristics under various operating conditions

\begin{tabular}{|c|l|c|}
\hline Cases & \multicolumn{1}{|c|}{ Description } & $\begin{array}{c}\text { Damping ratio \% } \\
\text { (Frequency Hz) }\end{array}$ \\
\hline Case 1 & 2013 generation & $7.36(0.69)$ \\
\hline Case 2 & 2023 generation, no wind & $6.22(0.71)$ \\
\hline Case 3 & $\begin{array}{l}\text { 2023 generation, 70\% wind } \\
\text { distributed across grid }\end{array}$ & $6.72(0.69)$ \\
\hline Case 4 & $\begin{array}{l}\text { 2023 generation, 70\% wind } \\
\text { at north, 10\% at south }\end{array}$ & $7.74(0.69)$ \\
\hline Case 5 & $\begin{array}{l}\text { 2023 generation, 10\% wind } \\
\text { at north, 70\% at south }\end{array}$ & $8.31(0.7)$ \\
\hline
\end{tabular}

The analysis shows that the inter-area mode will continue to cause a bottleneck in the transmission corridor. Although the HVDC lines provide additional transmission capacity, the level of wind penetration in Scotland can touch the loading limit of the ac transmission system. A Monte carlo simulation considering different generation profiles based on generator technology can produce more realistic operating conditions and can provide more insight to variation in damping of the mode.

\section{A. Effect of distributed wind farm}

One of the important assumptions in the model is the aggregation of wind farms in which a number of wind farms located at one area is considered as one WTG in the RGBN model. The effect of distributed small wind farms will be different from a large aggregated wind farm. Hence the care must be taken while making judgement on the simulation results.

\section{CONCLUSION}

The paper presents a test system to study the impact of large scale renewable integration in future GB transmission network. Two configurations representing 2013 and 2023 operating scenarios are presented. They can be used to generate realistic operating conditions of the system with large wind penetration. Modal analysis of the study system shows that the well observed Scotland England inter-area mode may limit transmission capacity and potentially reduce utilization of available clean wind power. 
TABLE II: Generating stations in the RGBN model

\begin{tabular}{|l|l|l|l||l|l|l|l|}
\hline $\begin{array}{l}\text { Bus } \\
\text { No. }\end{array}$ & Generator & 2012 & 2023 & $\begin{array}{l}\text { Bus } \\
\text { No. }\end{array}$ & $\begin{array}{l}\text { Generator } \\
\text { Type }\end{array}$ & 2012 & 2023 \\
\hline Bus 1 & Wind Onshore & 834 & 2641 & & Wind Onshore & 0 & 77 \\
& Wind Offshore & 0 & 1885 & & Hydro & 2083 & 2083 \\
& Hydro & 811 & 811 & B15 & Coal & 7832 & 6832 \\
Bus 2 & CCGT & 1180 & 1180 & & Wind Onshore & 32 & 32 \\
& Wind Onshore & 197 & 237 & B16 & CCGT & 9253 & 10258 \\
& Hydro & 18 & 18 & & Coal & 5205 & 5257 \\
Bus 3 & Wind Onshore & 348 & 551 & & Wind Offshore & 0 & 1118 \\
& Hydro & 552 & 552 & B17 & Coal & 2000 & 1500 \\
Bus 4 & Coal & 2407 & 2459 & B18 & CCGT & 128 & 1118 \\
& Wind Onshore & 35 & 70 & & Coal & 2218 & 1718 \\
& Wind offshore & 0 & 262 & B19 & CCGT & 3555 & 5030 \\
& Hydro & 440 & 440 & & Wind Offshore & 1483 & 2733 \\
Bus 5 & Nuclear & 890 & 890 & B20 & Nuclear & 1190 & 1990 \\
Bus 6 & Wind Onshore & 1400 & 2200 & B21 & CCGT & 700 & 600 \\
& Wind Offshore & 0 & 262 & B22 & CCGT & 900 & 1900 \\
Bus 7 & Nuclear & 1210 & 1210 & B23 & CCGT & 7000 & 7500 \\
& Wind Onshore & 466 & 886 & & Coal & 3541 & 2105 \\
& Wind Offshore & 0 & 875 & & Wind Onshore & 0 & 975 \\
B10 & CCGT & 196 & 196 & B25 & CCGT & 2800 & 2000 \\
& Coal & 420 & 420 & B26 & CCGT & 2300 & 2475 \\
& Nuclear & 1190 & 1190 & & Coal & 3000 & 1000 \\
& Wind Offshore & 184 & 2434 & B27 & Nuclear & 1040 & 0 \\
& CCGT & 1000 & 1800 & & Wind Offshore & 1020 & 3027 \\
& Coal & 2352 & 2352 & B28 & CCGT & 2550 & 1514 \\
& Nuclear & 2370 & 2370 & & Coal & 158 & 199 \\
& Wind Offshore & 1248 & 2528 & B29 & Wind Offshore & 0 & 1353 \\
& CCGT & 1934 & 2000 & & CCGT & 1055 & 1055 \\
& Nuclear & 428 & 428 & & Nuclear & 870 & 870 \\
\hline
\end{tabular}

\section{ACKNOWLEDGEMENT}

The financial support from the Marie Curie FP7-IAPP project "sing real-time measurements for monitoring and management of power transmission dynamics for the Smart Grid - REAL-SMART", Contract No: PIAP-GA-2009251304 is gratefully acknowledged.

\section{REFERENCES}

[1] National Grid: Electricity Ten Year Statement 2012. National Grid, November 2012.

[2] (2012, Novermber) Large combustion plants directive. European Commission. [Online]. Available: $\mathrm{http} / / / \mathrm{ec}$.europa.eu/environment/air/pollutants/stationary/lcp/legislation.h

[3] National Electricity Transmission System Seven Year Statement. National Grid, May 2011.

[4] P. Hitchin, "Is europe ready for the ied and willing?" Power Engineering International, pp. 40-45, 2011.

[5] UK Renewable Energy Roadmap. Department of Energy \& Climate Change, July 2011.

[6] UK Future Energy Scenarios. National Grid, September 2012.

[7] New nuclear power stations. [Online]. Available: https://www.gov.uk/government/policies/increasing-the-use-of-lowcarbon-technologies/supporting-pages/new-nuclear-power-stations

[8] Y. Du and J. Parsons, "Update on the cost of nuclear power," Center for Energy and Environmental Policy Research (CEEPR) No, pp. 09004, 2009.

[9] (2013, February) Centrica announces decision not to participate in uk nuclear new build and launches 500 million share repurchase programme. Centrica. [Online]. Available: http://www.centrica.com/index.asp?pageid=1041\&newsid=2646
[10] (2010, October 2010) Written ministerial statement on energy policy: The rt hon chris huhne mp,18 october 2010. [Online]. Available: https://www.gov.uk/government/news/written-ministerial-statementon-energy-policy-the-rt-hon-chris-huhne-mp-18-october-2010

[11] P. Pearson and J. Watson, "Uk energy policy 1980-2010: A history and lessons to be learnt," The IET and the Parliamentary Group for Energy Studies, London, Tech. Rep., 2012.

[12] Rwe generation. [Online]. Available: http://www.rwe.com/web/cms/en/97662/rwe-npower/about-us/ourbusinesses/power-generation/

[13] E.on uk's coal and oil fired power stations. [Online]. Available: http://www.eon-uk.com/generation/lcpd.aspx

[14] Sse ferrybridgepowerstation. [Online]. Available: http://www.sse.com/Ferrybridge/FerrybridgePowerStation/

[15] Wind Energy in the UK: State of the Industry Report 2012. renewableUK, October 2012.

[16] C. Barclay, "Consents for wind farms - onshore," House of Commons, Tech. Rep., 2012.

[17] M. Landy, "Analysis of renewables growth to 2020," AEA Technology plc, Tech. Rep., 2010.

[18] Greenwire project. [Online]. Available: http://www.greenwire.ie/

[19] K. Bell and A. Tleis, "Test system requirements for modelling future power systems," in IEEE Power and Energy Society General Meeting, 2010 , july 2010 , pp. $1-8$.

[20] "Representative model of the gb transmission system." [Online]. Available: http://www.supergennetworks.org.uk/filebyid/748/RepresentativeGBNetwork.pdf

[21] (2013, February) Alderney renewable energy. [Online]. Available: http://www.are.gb.com/

[22] P. Kundur, Power System Stability and Control. McGraw-Hill, 1994.

[23] W. E. C. C. Modeling and V. W. Group, WECC Wind Power Plant Dynamic Modeling Guide, WECC Renewable Energy Modeling Task Force, August 2010. 